\title{
A conservative programme for treatment of anterior knee pain in adolescents
}

\author{
Jacqueline Phillips (BSc Hons Biokinetics) \\ Marius F Coetsee (PhD)
}

Department of Human Movement Science, University of Zululand, KwaDlangezwa

\begin{abstract}
Objective. The purpose of this study was to determine the effectiveness of a $2 \frac{1}{2}$-week conservative rehabilitation programme in addressing anterior knee pain in adolescents.

Design. Subjects were randomly allocated to a control group $(N=12)$ and an experimental group $(N=18)$. The experimental group was subjected to a $2 \frac{1}{2}$-week strength, flexibility and neuromuscular rehabilitation programme. Both groups were tested before and after the $2 \frac{1}{2}$ weeks and the experimental group also 1 month after the post-test.
\end{abstract}

Results. The experimental group reported significant $(p<0.01)$ improvement in pain (Visual Analogue Scale), disability (Patient-Specific Functional Scale) and condition

\section{CORRESPONDENCE:}

Professor MF Coetsee

University of Zululand

Private Bag X1001

KwaDlangezwa

3886

Tel: 2735 772-6639

E-mail: mcoetsee@absamail.co.za
(Scale for Change in Condition). The experimental group tested significantly $(p<0.01)$ better for strength (quadriceps and hamstrings), flexibility (quadriceps, hamstrings and gastrocnemius) and neuromuscular control (Willknox wobble board and Bass test of dynamic balance). The control group experienced no improvement in any of the tests.

Conclusions. The $2 \frac{1}{2}$-week rehabilitation programme for addressing anterior knee pain in adolescents proved to be effective. The study demonstrated good retention of improvements and even further improvement after cessation of the programme. Advantages are the short duration and the fact that patients are familiarised with a home programme which they are likely to continue with. Although not addressed in this study, literature indicates that restoration of neuromuscular control might be the main contributing factor for the success of the programme.

\section{Introduction}

Anterior knee pain is a common condition that affects a wide age range of patients. ${ }^{5}$ The condition is often self-limiting, but can take up to 2 years to resolve. ${ }^{16}$ It frequently interferes with exer- 
cise and sports participation, and as a result a large number of adolescents may be forced to limit their participation in physical activity or perform sub-optimally on the sports field. ${ }^{8,27,4}$ Inactivity negatively affects physical development, general fitness, body composition, the development of motor skills and psychosocial development in growing children. ${ }^{16,6}$

There is a lack of consensus in the literature, especially in earlier studies, as to the exact definition of anterior knee pain. Anterior knee pain, patello-femoral pain, chondromalacia patella and patello-femoral arthralgia were used interchangeably in the past. One of the most common abnormalities involving the knee joint is disturbance of the patello-femoral mechanism. ${ }^{23}$ Over the years a number of stereotypical symptoms have been identified, namely: pain in the vicinity of the patella worsened by prolonged sitting, ascending or descending stairs, squatting and vigorous physical activity. ${ }^{5,27,21}$ The onset of anterior knee pain is insidious, and tends to be bilateral. ${ }^{21,24,17}$ The condition is common among adolescents and young adults, especially females. ${ }^{27,24,7}$ The exact aetiology is unknown but a number of predisposing factors have been suggested as possible causes. ${ }^{27}$ These include overuse, muscle imbalance, muscle tightness, trauma, overweight, genetic predisposition, valgus or varus knee, external tibial torsion, increased $Q$ angle, abnormal mechanics of the foot and ankle, especially pronation, and generalised ligament laxity. ${ }^{27,17,13}$ In many cases it appears that the onset of anterior knee pain coincides with the period of the adolescent growth spurt. ${ }^{19}$ Surgical intervention is not recommended and often there is no demonstrable anatomical abnormality. ${ }^{16}$ Conservative treatment for anterior knee pain should always be the first approach. ${ }^{22}$ Many studies reported good results with conservative treatment. ${ }^{26,13,28}$

Rehabilitation programmes reported in the literature lasted between 6 and 12 weeks. ${ }^{27,4,13}$ However, practical experience in the South African context has shown that patient compliance is poor with a programme that exceeds 3 weeks. Many years of experience in a biokinetic (physical therapy) practice have evolved a rehabilitation protocol of $2 \frac{1}{2}$ weeks for knee rehabilitation that is perceived to be highly successful. This programme concentrates on improvement of strength, flexibility and especially neuromuscular control in an attempt to stabilise the knee joint.

The focus of this study was therefore to test the effective-ness of a $2 \frac{1}{2}$-week physical rehabilitation programme in alleviating anterior knee pain in adolescents. The term anterior knee pain is used to describe the symptom complex characterised by pain in the anterior region of the knee during activity in the absence of an identifiable pathological condition.

\section{Methods}

Approval for the study was obtained from the Faculty of Science and Agriculture Ethics Committee, University of Zululand. All subjects and their parents completed an informed consent form prior to testing. Potential subjects were identified from responses to an article that appeared in the local newspaper, referrals from doctors and from responses to a questionnaire distributed to pupils at 9 local schools. Subjects had to be between the ages of 10 and 17 years and both males and females were eligible. Criteria for positive anterior knee pain were: pain on the anterior surface of the knee in excess of 1 month's duration, pain intensity of moderate to severe and pain that interfered with sport participation. Exclusion criteria were: previously diagnosed ligamentous, meniscal, tendon, fat pad or bursae involvement; previous surgery; history of patella dislocation or subluxation; Osgood-Schlatter's disease and Sinding-Larsen-Johannsen disease. Skyline, lateral and anteroposterior view X-rays were taken of potential candidates. Final subject selection was determined by an orthopaedic surgeon after a physical examination and examination of the X-rays.

Subjects meeting the above criteria were randomly allocated to either the control or experimental group. The control group $(N=12)$ underwent pre-testing and $2 \frac{1}{2}$ weeks later post-testing, and continued with normal everyday activity over this period. The experimental group $(N=18)$ underwent pre-testing, 21/2-week intervention, post-testing and post-post testing 1 month postintervention. The intervention programme was offered to the subjects of the control group after the post-tests were concluded. Subjects were dressed in a T-shirt, shorts and exercise shoes during testing.

The following three subjective tests were selected to quantify reduction in pain and disability:

- Pain was rated using the Visual Analogue Scale (VAS). The VAS has been found to be a reliable and valid tool for measuring pain. ${ }^{27,12}$ It has also been shown to be a valid indicator of pain changes in patients with anterior knee pain. ${ }^{18}$ The VAS is a $10-\mathrm{cm}$ horizontal line marked at $1-\mathrm{cm}$ intervals, the ends of which define the minimum (no pain) and maximum (severe pain) of perceived pain. Subjects indicated the intensity of their pain with a mark on the line. Normal, least and worst pain experienced in the past week was documented.

- Level of disability was rated using the Patient-Specific Functional Scale (PSFS). ${ }^{3}$ Test-retest reliability is excellent, and it is a valid and responsive tool. ${ }^{3,11}$ This instrument aids clinicians in assessing the change in health or functional status of individual patients. ${ }^{3,25}$ Patients were asked to identify up to 5 activities which they were experiencing difficulty with or were unable to perform because of their knee pain and then to rate the current level of difficulty associated with each activity from 0 (unable to perform activity) to 10 (able to perform activity at same level as before injury or problem).

- Overall improvement at the post-test and post-post-test was measured using the Scale for Change in Condition. ${ }^{9}$ This 4point scale is useful for assessing the change in functional status of individual patients. ${ }^{9}$

The following six objective tests were selected for measurement of performance:

- Measurements of maximal quadriceps and hamstring muscle strength were recorded during closed-kinetic-chain isometric knee flexion and extension using a dynamometer. The testretest reliability was determined in a pilot study using healthy subjects. Subjects were positioned with the knee at 90 degrees of flexion and given one practice trial, whereafter the highest value of three attempts was recorded. Subjects rested for 30 seconds between attempts.

- The Straight Leg Hamstring Test was used to measure hamstring flexibility. ${ }^{29}$ The subject lay supine on the plinth 
TABLE I. Intervention programme followed during contact sessions

\begin{tabular}{|c|c|c|c|c|c|}
\hline $\begin{array}{l}\text { Intervention } \\
\text { modality }\end{array}$ & Activity & $\begin{array}{l}\text { Speed or } \\
\text { intensity }\end{array}$ & Repetitions & Sets & Rest \\
\hline Open-kinetic-chain & $50-60 \%$ effort & 120 deg.s $\mathrm{s}^{-1}$ & 10 & 3 & \\
\hline Isokinetic knee & & 100 deg.s $\mathrm{s}^{-1}$ & 10 & & \\
\hline Warm-up and & & 80 deg.s $\mathrm{s}^{-1}$ & 8 & & $20 \mathrm{~s}$ \\
\hline \multirow[t]{2}{*}{ strengthening } & $100 \%$ effort & 60 deg.s $\mathrm{s}^{-1}$ & 6 & $2-3$ & \\
\hline & & 40 deg. $\mathrm{s}^{-1}$ & 4 & & \\
\hline Wobble board & Balancing & Max effort & $2 \min$ & & \\
\hline Mini-trampoline & Jog & Maintaining & $30 \mathrm{~s}$ & & \\
\hline \multirow[t]{6}{*}{ Routine } & 2 bounce/leg & neuro- & $30 \mathrm{~s}$ & & \\
\hline & 3 bounce/leg & muscular & $30 \mathrm{~s}$ & 1 & Continuous \\
\hline & 1 leg only bounce & control at & $2 \times 15 s$ & & \\
\hline & 2 leg bounce & all times & $30 \mathrm{~s}$ & & \\
\hline & Twist & & $30 \mathrm{~s}$ & & \\
\hline & 1 leg twist & & $2 \times 15 s$ & & \\
\hline \multirow{6}{*}{$\begin{array}{l}\text { Mat jumping } \\
\text { routine }\end{array}$} & 1. Forward - back & Maintaining & & & \\
\hline & 2. Side - side & neuro- & & & \\
\hline & 3. Clockwise & muscular & & 1 & \\
\hline & 4. Anti-clockwise & control at & $3-5 x$ & & $5 \mathrm{~s}$ \\
\hline & 5. Cross forwards & all times & & & \\
\hline & 6. Cross backwards & & & & \\
\hline
\end{tabular}

with one leg secured to the plinth to prevent hip flexion. The other leg was passively lifted by the researcher flexing the hip joint until the hamstring started to flex the knee. The angle of hip flexion was measured using a goniometer.

- The Modified Thomas Test was used to measure flexibility of the quadriceps muscles. ${ }^{10}$ The subject sat on the end of the plinth, and rolled back pulling both knees to the chest. This ensured that the pelvis was in posterior rotation and that the lumbar spine was flat on the plinth. The subject then lowered one leg towards the floor while holding the contralateral limb in maximum flexion with the arms. The angle of knee flexion was measured.

- The Straight Leg Gastrocnemius test was used to measure flexibility of the gastrocnemius. ${ }^{29}$ The patient positioned the foot of the leg being measured on a mark $0.6 \mathrm{~m}$ from the plinth and with the hands on the plinth leant forward as far as pos- sible while keeping the heel on the floor and the leg straight. The other leg was used for balance, and was bent. The angle of ankle dorsiflexion was measured.

- Proprioception (neuromuscular control) of the lower limbs was measured on the Willknox wobble board, which is an apparatus built at the University of Zululand and records the time that the rim of the wobble board touches the floor. The subject balanced on the wobble board while trying not to touch the rim to the floor but, most importantly, if the rim did touch to lift it as quickly as possible. Time that the rim touched the floor during a 2-minute period was recorded.

- The Bass Test of Dynamic Balance ${ }^{2}$ was used to measure dynamic balance. A reliability coefficient of 0.95 was obtained with female college students as subjects. The subject stood with the right foot in the starting circle, jumped into the first circle with the left foot and thereafter jumped from circle to circle, alternating the feet. The subject had to land on the ball

TABLE II. Percentage differences between pre- v. post- and pre- v. post-post mean ratings of worst, least and normal pain (points) as indicated on the visual analogue scale (VAS), for the control $(N=12)$ and experimental ( $N=18)$ groups. Points data expressed as mean \pm SD

\begin{tabular}{|c|c|c|c|c|c|c|}
\hline Group & $\begin{array}{l}\text { Worst pre } \\
\text { v. post }\end{array}$ & $\begin{array}{l}\text { Worst pre } \\
\text { v. post-post }\end{array}$ & $\begin{array}{l}\text { Least } \\
\text { pre v. post }\end{array}$ & $\begin{array}{l}\text { Least pre } \\
\text { v. post- } \\
\text { post }\end{array}$ & $\begin{array}{l}\text { Normal } \\
\text { pre v. } \\
\text { post }\end{array}$ & $\begin{array}{l}\text { Normal } \\
\text { pre v. } \\
\text { post-post }\end{array}$ \\
\hline \multirow[t]{3}{*}{ Control } & $6.6 \pm 0.9 \mathrm{v}$ & N/A & $2.5 \pm 0.9 \mathrm{v}$ & $N / A$ & $4.6 \pm 1.4 \mathrm{v}$ & $\mathrm{N} / \mathrm{A}$ \\
\hline & $6.8 \pm 0.7$ & & $3.0 \pm 0.5$ & & $4.6 \pm 0.8$ & \\
\hline & $+3.0 \%$ & & $+20.0 \%^{\dagger}$ & & $0 \%$ & \\
\hline \multirow[t]{3}{*}{ Experimental } & $7.1 \pm 1.2 \mathrm{v}$ & $7.1 \pm 1.2 v$ & $3.3 \pm 1.8 \mathrm{v}$ & $3.3 \pm 1.8 \mathrm{v}$ & $5.4 \pm 1.9 \mathrm{v}$ & $5.4 \pm 1.9 \mathrm{v}$ \\
\hline & $4.0 \pm 0.9$ & $4.1 \pm 1.0$ & $2.1 \pm 1.2$ & $2.1 \pm 0.8$ & $3.1 \pm 1.3$ & $3.2 \pm 1.5$ \\
\hline & $-43.0 \%^{*}$ & $-42.8 \%^{*}$ & $-35.3 \%$ * & $-37.5 \% *$ & $-42.0 \% *$ & $-41.6 \%{ }^{*}$ \\
\hline${ }^{*} p<0.01$ & & & & & & \\
\hline$\dagger_{p<0.05)}$ & & & & & & \\
\hline
\end{tabular}




\begin{tabular}{|c|c|c|c|c|c|}
\hline Group & Pre & Post & $\begin{array}{l}\text { Difference } \\
\text { pre v. post }\end{array}$ & $\begin{array}{l}\text { Post- } \\
\text { post }\end{array}$ & $\begin{array}{l}\text { Difference } \\
\text { Pre v. post- } \\
\text { post }\end{array}$ \\
\hline Control & $\begin{array}{l}5.7 \\
\pm 1.2\end{array}$ & $\begin{array}{l}5.6 \\
\pm 1.1\end{array}$ & $-1.8 \%^{\dagger}$ & N/A & \\
\hline Experimental & $\begin{array}{l}5.6 \\
\pm 1.4\end{array}$ & $\begin{array}{l}7.8 \\
\pm 1.1\end{array}$ & $+39.3 \%$ * & $\begin{array}{l}8.2 \\
\pm 1.2\end{array}$ & $+46.4 \%$ * \\
\hline${ }^{*} p<0.01$ & & & & & \\
\hline
\end{tabular}

of the foot, and not allow the heel to touch the ground. Each error counted as a penalty point every time it occurred. Errors included the following: (i) the heel touching the ground; (ii) moving or hopping on the supporting foot while in the circle; (iii) touching the floor outside a circle with the supporting foot; and (iv) touching the floor with the free foot or any other part of the body. The timer counted the seconds (up to 5 seconds) out loud, beginning the count as the subject landed in the circle. Counting was restarted if the performer leapt to the next circle in less than 5 seconds. If the subject spent more than 5 seconds in the circle, the extra time was deducted from the total time. Errors were counted silently and cumulatively by the tester, who followed the subject closely. A total of 5 trials were given, 3 of which were practice runs. The final score was the total time plus 50 , minus 3 times the total number of errors. The better score of the last 2 trials was used.

The intervention programme included muscle strength, proprioception and dynamic stability training done during 5 contact sessions of 45 minutes each and 5 home sessions of 30 minutes each. The contact sessions as shown in Table I included the following: strengthening of the quadriceps and hamstring muscles through isokinetic open-kinetic-chain knee flexion and extension exercises, proprioception and dynamic joint stability training through wobble board balancing, a routine on the mini-trampoline and from the third session a functional jumping routine. The intensity of the exercises was adapted to the specific condition and ability of each subject. Particular attention was given during the proprioception and joint stability training not to cause further pain as this would have caused inhibition of the stabilising muscles and therefore would have been counterproductive. The home programme included the following: stretching of the hamstrings, quadriceps/hip flexors and calf muscle groups; strengthening of the knee flexor/extensor, ankle plantar/dorsiflexor and hip flexor/extensor muscle groups by means of callisthenic type exercises that could be done without any apparatus; and proprioception done by means of the stork stand on a plank of $2.5 \mathrm{~cm}$ wide for 1 minute per leg. The subjects were introduced to the home programme during the second contact session. They then followed the programme on their own on different days from the contact sessions. An exercise log was kept by subjects to enhance compliance.

Data were analysed using descriptive statistics, t-tests and the Wilcoxon Signed Rank test.

\section{Results}

Subjects had a mean age of 14.3 years, mean height of $1.7 \mathrm{~m}$ and mean weight of $59.7 \mathrm{~kg}$. The mean duration of anterior knee pain for the subjects selected for the study was 16 months. Although the subjects were randomly allocated to the control and experimental groups, the control group subjects were slightly older, taller and heavier than the experimental group subjects but the differences were not statistically significant $(p>0.05)$. It was thus concluded that the control group met the criteria for comparison with the experimental in a study of this nature.

Table II shows that the intervention programme resulted in a significant $(p<0.01)$ reduction in worst, least and normal pain ratings at the post-testing, and this was maintained 1 month later at the post-post testing. There was no significant change in the control group apart from least pain, which increased significantly $(p<0.05)$ at the post-test. The positive change in VAS points for worst, least and normal pain in the experimental group at post-testing was $3.1,1.2$ and 2.3 points respectively. A change of 1.0 point on the 10 point $(\mathrm{cm})$ VAS is reported to be the minimum required to indicate a clinically important change. ${ }^{4,9}$ It can therefore be assumed that the intervention programme was successful in reducing pain.

Subjects individually indicated particular activities on the Patient Specific Functional Scale that they were experiencing difficulty with due to their knee pain. The activities reported in order of importance were: running, jumping, stair climbing, sitting, cross-legged sitting and twisting movements. Table III shows that on completion of the intervention programme, subjects from the experimental group reported a significantly $(p<0.01)$ improved ability to perform these same activities. This reduced disability was maintained at the post-post testing $(p<0.01)$. No change occurred in the control group. Thus it can be concluded that participation in the intervention programme resulted in decreased disability due to anterior knee pain, which was maintained in the long term.

Table IV shows that the subjects of the control group experienced the same or worse pain at the post-test when compared with the pre-test, while all the subjects in the experimental group indicated an improvement in their condition. Most of the subjects in the experimental group reported that their condition was at least as good or better at the post-post test compared with the post-test. The results indicate that the benefits derived from the intervention programme were largely retained after the intervention was stopped.

There was a significant $(p<0.01)$ gain in muscle strength in both the quadriceps (11.5\%) and hamstring (14.2\%) muscle groups at the post-test and a further $1.2 \%$ in the quadriceps and $1.4 \%$ in the hamstrings at post-post test in the experimental group. No significant $(p>0.05)$ change was found in the control group. 
TABLE IV. Percentage change in condition in the control $(N=12)$ and experimental $(N=18)$ groups as measured by the Scale for Change in Condition between the pre- and post-, and post and post-post tests

\begin{tabular}{|c|c|c|c|c|c|}
\hline Comparison & $\begin{array}{l}\text { Great } \\
\text { improvement } \\
(\%)\end{array}$ & $\begin{array}{l}\text { Improve- } \\
\text { ment } \\
(\%)\end{array}$ & $\begin{array}{l}\text { No } \\
\text { change } \\
(\%)\end{array}$ & $\begin{array}{l}\text { Deterio- } \\
\text { ration } \\
(\%)\end{array}$ & $\begin{array}{l}\text { Not } \\
\text { tested } \\
(\%)\end{array}$ \\
\hline Control group $(N=12)$ & 0.0 & 0.0 & 75 & 25 & \\
\hline \multicolumn{6}{|l|}{ Pre v. Post } \\
\hline Experimental $(N=18)$ & 33.3 & 66.7 & 0.0 & 0.0 & \\
\hline \multicolumn{6}{|l|}{ Pre v. Post } \\
\hline \multicolumn{6}{|l|}{ Experimental $(N=18)$} \\
\hline Post v. & 27.8 & 27.8 & 11.1 & 16.7 & 16.7 \\
\hline
\end{tabular}

TABLE V. Percentage difference in mean muscle flexibility (degrees) of the control $(N=12)$ and experimental $(N=18)$ groups between the pre- and post-, and pre- and post-post testing. Data are expressed as the mean \pm SD.

\begin{tabular}{|c|c|c|c|c|c|c|}
\hline $\begin{array}{l}\text { Group } \\
\text { and } \\
\text { side }\end{array}$ & $\begin{array}{l}\text { Quadri- } \\
\text { ceps } \\
\text { pre v. post }\end{array}$ & $\begin{array}{l}\text { Quadri- } \\
\text { ceps } \\
\text { pre v. } \\
\text { post-post }\end{array}$ & $\begin{array}{l}\text { Ham- } \\
\text { strings } \\
\text { pre v. post }\end{array}$ & $\begin{array}{l}\text { Hams- } \\
\text { trings } \\
\text { pre v. } \\
\text { post-post }\end{array}$ & $\begin{array}{l}\text { Gastroc- } \\
\text { nemius } \\
\text { pre v. post }\end{array}$ & $\begin{array}{l}\text { Gastroc- } \\
\text { nemius pre } \\
\text { v. post-post }\end{array}$ \\
\hline Control & $65.9 \pm 9.6 \mathrm{v}$ & $N / A$ & $57.4 \pm 7.7 \mathrm{v}$ & $N / A$ & $67.8 \pm 4.8 \mathrm{v}$ & $N / A$ \\
\hline Right & $65.8 \pm 9.4$ & & $57.5 \pm 7.8$ & & $67.8 \pm 4.7$ & \\
\hline$\%$ change & $-0.2 \%^{\dagger}$ & & $+0.2 \%^{\dagger}$ & & $0 \%^{\dagger}$ & \\
\hline \multirow[t]{2}{*}{ Control Left } & $62.6 \pm 10.3 \mathrm{v}$ & $\mathrm{N} / \mathrm{A}$ & $58.0 \pm 5.5 \mathrm{v}$ & $N / A$ & $69.6 \pm 6.2 v$ & $\mathrm{~N} / \mathrm{A}$ \\
\hline & $62.8 \pm 8.8$ & & $58.1 \pm 4.8$ & & $69.4 \pm 8.3$ & \\
\hline$\%$ change & $+0.3 \%^{\dagger}$ & & $+0.2 \%^{\dagger}$ & & $-0.3 \%^{\dagger}$ & \\
\hline \multirow[t]{2}{*}{ Exp. right } & $68.2 \pm 12.1 \mathrm{v}$ & $68.2 \pm 12.1 \mathrm{v}$ & $57.7 \pm 8.3 v$ & $57.7 \pm 8.3 \mathrm{v}$ & $66.7 \pm 3.8 \mathrm{v}$ & $66.7 \pm 3.8 \mathrm{v}$ \\
\hline & $70.7 \pm 7.7$ & $70.5 \pm 9.8$ & $59.5 \pm 5.6$ & $59.5 \pm 4.2$ & $68.7 \pm 5.8$ & $69.2 \pm 6.2$ \\
\hline$\%$ change & $+3.7 \%^{*}$ & $+3.4 \%{ }^{*}$ & $+3.1 \%{ }^{*}$ & $+3.1 \%{ }^{*}$ & $+3.0 \%$ * & $+3.7 \%{ }^{*}$ \\
\hline \multirow[t]{2}{*}{ Exp. left } & 66.1 v. 69.0 & 66.1 v. 68.8 & 56.5 v. 57.9 & 56.5 v. 58.8 & 66.8 v. 68.3 & 66.8 v. 68.3 \\
\hline & \pm 10.8 v. 8.9 & \pm 10.8 v. 7.5 & \pm 8.0 v. 6.5 & \pm 8.0 v. 9.2 & \pm 6.0 v. 3.8 & \pm 6.0 v. 4.4 \\
\hline$\%$ change & $+4.4 \%{ }^{*}$ & $+4.1 \%{ }^{*}$ & $+2.5 \%{ }^{*}$ & $+4.1 \%{ }^{*}$ & $+2.2 \%{ }^{*}$ & $+2.2 \% *$ \\
\hline $\begin{array}{l}{ }^{*} p<0.01 \\
\dagger_{p>0.05}\end{array}$ & & & & & & \\
\hline
\end{tabular}

Table $V$ shows a small but significant $(p<0.01)$ improvement in quadriceps, hamstring and gastrocnemius flexibility in the experimental group at the post- and post-post testing. There was no significant $(p>0.05)$ change in the control group.

Table VI show a large significant $(p<0.01)$ improvement in both proprioception and dynamic balance of the experimental group at the post- and post-post testing while the control group showed little $(p>0.05)$ change at the post-test.

\section{Discussion}

The main purpose of this study was to determine if a specific rehabilitation programme (Table I) of only $2 \frac{1}{2}$ weeks, which is substantially shorter than traditional programmes reported in literature, would effectively address the problem of anterior knee pain in adolescents. This approach was prompted by two factors experienced in years of private practise, namely that attendance of rehabilitation sessions declined substantially after 3 weeks, and that very good results were found with short programmes concentrating on strength, flexibility and especially neuromuscular control (dynamic proprioception). It was time to test the effectiveness of such a programme in alleviating anterior knee pain in adolescents.

Results of the three tests (Tables II, III and IV) measuring the impact of anterior knee pain on subjects and on their ability to function optimally clearly prove the success of the intervention programme. Subjects in the experimental group reported a substantial and significant $(p<0.01)$ reduction in worst $(43 \%)$, least $(35 \%)$ and normal (42\%) pain as measured on the Visual Analogue Scale while subjects in the control group reported nonsignificant $(p>0.05)$ changes for worst $(3 \%)$ and normal $(0 \%)$ pain but a significant $(p<0.05)$ increase $(20 \%)$ in least pain (Table II). The experimental group subjects reported substantial (39\%) and significant $(p<0.01)$ improvement in their ability to perform various activities as measured on the Patient Specific Functional Scale (Table III) while the control group deteriorated slightly $(2 \%)$ but not significantly $(p>0.05)$. Of the experimental group $33 \%$ of subjects reported 'great improvement' and 67\% 'improvement' 


\begin{tabular}{|c|c|c|c|c|}
\hline Group & $\begin{array}{l}\text { Wobble board } \\
\text { (seconds) } \\
\text { pre v. post }\end{array}$ & $\begin{array}{l}\text { Wobble board } \\
\text { (seconds) } \\
\text { pre v. post-post }\end{array}$ & $\begin{array}{l}\text { Bass test pre } \\
\text { v. post }\end{array}$ & $\begin{array}{l}\text { Bass test } \\
\text { pre v. post- } \\
\text { post }\end{array}$ \\
\hline \multirow[t]{2}{*}{ Control } & $32.2 \pm 13.4 \mathrm{v}$ & $\mathrm{N} / \mathrm{A}$ & $56.4 \pm 15.1 \mathrm{v}$ & $\mathrm{N} / \mathrm{A}$ \\
\hline & $31.1 \pm 8.9$ & & $58.3 \pm 14.6$ & \\
\hline$\%$ change & $-3.4 \%^{\dagger}$ & & $+3.4 \%^{\dagger}$ & \\
\hline \multirow[t]{2}{*}{ Experimental } & $30.3 \pm 13.5 \mathrm{v}$ & $30.3 \pm 13.5 \mathrm{v}$ & $47.7 \pm 17.4 \mathrm{v}$ & $47.7 \pm 17.4 v$ \\
\hline & $16.4 \pm 7.2$ & $14.9 \pm 7.9$ & $65.6 \pm 12.8$ & $73.1 \pm 13.0$ \\
\hline$\%$ change & $-45.9 \% *$ & $-50.8 \% *$ & $+37.5 \%{ }^{*}$ & $+53.2 \%{ }^{*}$ \\
\hline $\begin{array}{l}{ }_{p<0.01}^{*} \\
t_{p>0.05}\end{array}$ & & & & \\
\hline
\end{tabular}

as measured on the Scale for Change in Condition while $75 \%$ of the control group reported 'no change' and $25 \%$ a 'deterioration' (Table IV). After completing the rehabilitation programme subjects of the experimental group thus clearly experienced less pain, were able to perform activities which gave them problems before the intervention better, and perceived the anterior knee pain to have subsided substantially. From the subjects' point of view the rehabilitation programme was therefore a success.

In order for any programme, especially a programme of short duration, to be successful the benefits achieved must have a lasting effect once the programme is stopped. The results in Tables II and III, which compare the VAS and PSFS scores of the subjects before the start of the programme with those 1 month after cessation of the programme, indicate no deterioration and in some of the tests a further improvement. Least pain decreased a further $2 \%$ and the PSFS increased a further $8 \%$. The 'change in condition' results as shown in Table IV, which compares the condition of the subjects at the cessation of the programme with 1 month later, substantiate this further improvement. When the subjects $(17 \%)$ who failed to complete the post-post test were excluded from the calculation, the remaining subjects reported a further 'great improvement' of 33\%, an 'improvement' of 33\%, a 'no change' of $13 \%$ and a 'deterioration' of $20 \%$. The additional improvement experienced after the intervention programme was stopped can probably be attributed to improved neuromuscular control, which will be described further on.

Strength or, more accurately, the ability of the muscles of the knee to contract strongly when required should play an important role in alleviating anterior knee pain. After completion of the intervention programme the subjects of the experimental group were significantly $(p<0.01)$ stronger in the quadriceps and hamstrings. The control group was slightly weaker in the postthan in the pre-test. However, it is not clear if the improvement in strength is a cause for, or an effect of, the improvement in the condition (anterior knee pain). Clearly, inhibition of muscles of the knee caused by anterior knee pain would have precluded subjects from being able to apply full force during the pre-tests. Either way the rehabilitation programme resulted in greater force and thereby greater knee stability.

Due to the limited exposure to stretching exercises, which were only included in the home programme for the experimental group, large changes were not expected. Small but significant $(p<0.01)$ improvements were recorded in the quadriceps $(4 \%)$, hamstrings $(3 \%)$ and gastrocnemius $(3 \%)$ flexibility for the experimental group (Table $\mathrm{V}$ ). The control group did not show any change in flexibility. It is not clear if these improvements in flexibility were sufficient to have contributed to an improvement in the condition of anterior knee pain.

Proprioception is traditionally defined as the ability to determine the position of a joint in space at any given instant. The focus of the present study, however, was on proprioception as it relates to neuromuscular control and joint function. Table IV shows the results for the Willknox wobble board test, which was used as a measure of proprioception and the Bass test, which was used to measure dynamic balance. After conclusion of the intervention programme the experimental group showed a substantial $(46 \%)$ and significant $(p<0.01)$ reduction in time unbalanced on the wobble board while the control group only showed a small $(3 \%)$ but non-significant $(p>0.05)$ improvement. The Bass test showed a large $(38 \%)$ significant $(p<0.01)$ improvement in the experimental group but only a small $(3 \%)$ non-significant $(p>0.05)$ improvement in the control group. The improvement in the experimental group further increased to $51 \%$ (Willknox wobble board) and 53\% (Bass test) at the post-post test 1 month after the intervention programme was concluded. Good results in the Willknox wobble board test and the Bass test are dependent on proper neuromuscular control of the lower limb joints, especially the knee joint. The results of the present study could imply that restoration of proper neuromuscular control through proprioceptive and dynamic balance exercises probably played a major role in alleviating the symptoms of anterior knee pain in the subjects of the experimental group. An integrated relationship exists between proprioception, neuromuscular control and dynamic joint stability. ${ }^{14,20}$ Improvement in neuromuscular control helps to reduce inhibition caused by pain and instability in the knee joint, thus allowing the muscles to contract optimally and support the knee better. If pain is present it results in involuntary inhibition, whereby the patient is unwilling to maximally contract the muscles due to the pain or the fear of pain. ${ }^{18}$ Reflex inhibition is a limiting factor in rehabilitation as it restricts full muscle activation, thus preventing restoration of muscle strength. ${ }^{15}$ Once the pain 
inhibition is sufficiently removed the muscles increasingly fulfill their roles in joint stability and further improvement takes place spontaneously during normal daily use of the joint. Barrett ${ }^{1}$ went so far as to suggest that proprioception is a greater contributor to normal limb function during activity than muscle strength, which is a statement the current authors agree with. The restoration of proprioception and neuromuscular control is essential in a comprehensive conservative rehabilitation programme. ${ }^{14}$ The current rehabilitation programme could have been successful in re-establishing this neuromuscular control because the activities employed progressively forced the subjects to exercise at the boundary of neuromuscular control but never crossing the line where pain results in the loss of control.

\section{Limitations}

Possible limitations of this study were the lack of a placebo treatment in the control group and the absence of blinding procedures. Due to insufficient resources and for the sake of accuracy in treatment and testing, both researchers were involved in all the protocols. All possible precautions were taken to ensure reliability of the data.

\section{Conclusion}

The rehabilitation programme shown in Table I, complemented by the home programme as described in the methods section, has been shown to effectively address anterior knee pain in adolescents. Although not directly proven in this study, restoration of neuromuscular control is probably the main contributing factor for the reduction in anterior knee pain. The study also demonstrated good retention of improvements and even further improvement after cessation of the programme. This may be attributed to the ability of subjects to resume active participation in physical activities previously affected by the condition. Advantages of this particular programme is that good results can be effected in 5 sessions over $2 \frac{1}{2}$ weeks and that patients are familiarised with a home programme which they know works and which they are likely to continue with.

\section{Practical implications}

This study provides an exercise regimen that successfully addresses knee pain in adolescents. The harmful effects of forced inactivity on the physical development of children can be avoided by following this programme.

\section{Acknowledgements}

This study was supported financially by the University of Zululand, South Africa.

\section{REFERENCES}

1. Barrett DS. Proprioception and function after anterior cruciate ligament reconstruction. J Bone Joint Surg Br 1991; 73: 833-7.

2. Bosco JS, Gustafson WF. Measurement and Evaluation in Physical Education, Fitness, and Sports. New Jersey: Prentice-Hall, 1983.
3. Chatman AB, Hyams SP, Neel JM, et al. The Patient-Specific Functional Scale: Measurement properties in patients with knee dysfunction. Phys Ther 1997; 77(8): 820-9.

4. Crossley K, Bennell K, Green S, Cowan S, McConnell J. Physical therapy for patello-femoral pain: A randomized, double-blinded, placebo-controlled trial. Am J Sports Med 2000; 30(6): 857-65.

5. Cutbill JW, Ladly KO, Bray RC, Thorne P, Verhoef M. Anterior knee pain: A review. Clin J Sport Med 1997; 7: 40-5.

6. Difiori JP. Overuse injuries in children and adolescents. The Physician and Sports Medicine 1999; 27(1): 75-89.

7. Dugan SA. Sports-related knee injuries in female athletes. What gives? Am J Phys Med Rehabil 2005; 84(2): 122-9.

8. Galanty HL, Matthews C, Hergenroeder AC. Anterior knee pain in adolescents. Clin J Sport Med 1994; 4: 176-81.

9. Harrison E, Quinney H, Magee D, Sheppard MS, McQuarrie A. Analysis of outcome measures used in the study of patello-femoral pain syndrome. Physiother Can 1995; 47(4): 264-72.

10. Harvey D. Assessment of the flexibility of elite athletes using the modified Thomas test. Br J Sports Med 1998; 32: 68-70.

11. Jolles BM, Buchbinder R, Beaton DE. A study compared nine patientspecific indices for musculoskeletal disorders. J Clin Epidemiol 2005; 58: 791-801.

12. Kane RL, Bershadsky B, Rockwood T, Saleh K, Islam NC. Visual analog scale reporting was standardized. J Clin Epidemiol 2005; 58: 618-23.

13. Karlsson J, Thomee R, Sward L. Eleven-year follow-up of patello-femoral pain syndrome. Clin J Sport Med 1996; 6: 22-6.

14. Lephart SM, Pincivero DM, Rozzi SL. Proprioception of the ankle and knee. Sports Med 1998; 25(3): 149-55.

15. Palmieri RM, Ingersoll CD, Edwards JE, et al. Arthrogenic muscle inhibition is not present in the limb contralateral to a simulated knee joint effusion. Am J Phys Med Rehabil 2003; 82(12): 910-6.

16. Patel DR, Nelson TL. Sports injuries in adolescents. Med Clin North Am 2000; 84(4): 983-1005.

17. Pollock D. Clinical examination of the patello-femoral joint. SA Orthop J 2004; 3(4): 8-10

18. Powers CM, Landel R, Perry J. Timing and intensity of vastus muscle activity during functional activities in subjects with and without patello-femoral pain. Phys Ther 1996; 76(9): 946-67.

19. Rogan IM. Anterior knee pain in the sporting population: Forum. SA Bone and Joint Surg 1995; 5(2): 28-30.

20 Sharma L. Proprioceptive impairment in knee osteoarthritis. Rheum Dis Clin North Am 1999; 25(2): 299-314.

21. Shea KG, Pfeiffer R, Curtin M. Idiopathic anterior knee pain in adolescents. Orthop Clin North Am 2003; 34(3): 377-83.

22. Shelton GL, Thigpen LK. Rehabilitation of patello-femoral dysfunction: a review of literature. J Orthop Sports Phys Ther 1991; 14(6): 243-9.

23. Souza DR, Gross MT. Comparison of vastus medialis obliquus: vastus lateralis muscle integrated electromyographic ratios between healthy subjects and patients with patello-femoral pain. Phys Ther 1991; 71(4): 31020.

24. Stanitski CL. Anterior knee pain syndromes in the adolescent. J Bone Joint Surg Br 1993; 75(9): 1407-16.

25. Stratford PW, Kennedy DM, Hanna SE. Condition-specific Western Ontario McMaster Osteoarthritis Index was not superior to region-specific Lower Extremity Functional Scale in detecting change. J Clin Epidemiol 2004; 57: 1025-32.

26. Thomee R. A comprehensive treatment approach for patello-femoral pain syndrome in young women. Phys Ther 1997; 77(12): 1690-703.

27. Thomee R, Augustsson J, Karlsson J. Patello-femoral pain syndrome: A review of current issues. Sports Med 1999; 28(4): 245-62.

28. Tria AJ, Palumbo RC, Alicea JA. Conservative care for patello-femoral care. Orthop Clin North Am 1992; 23(4): 545-54.

29. Witvrouw E, Lysens R, Bellemans J, Peers K, Vanderstraeten G. Open versus closed kinetic chain exercises for patello-femoral pain. $A m \mathrm{~J}$ Sports Med 2000; 28(5): 687-94. 